\title{
Student satisfaction with library resources in the COVID-19 era: \\ a case study of Portuguese academic libraries
}

\author{
Maria Luz Antunes ${ }^{1,2}$, Carlos Lopes ${ }^{2,3}$, Tatiana Sanches ${ }^{2,4}$ \\ 1. ESTeSL (Instituto Politécnico de Lisboa), Lisboa, Portugal. \\ 2. APPsyCl-Applied Psychology Research Center Capabilities and Inclusion, Lisboa, Portugal. \\ 3. ISPA - Instituto Universitário, Lisboa, Portugal. \\ 4. UIDEF, Instituto da Educação, Universidade de Lisboa, Lisboa, Portugal
}

\section{Introduction}

Academic libraries aim to provide access to information to students, teachers, and researchers, ensuring their satisfaction with their needs. The behaviour of the students in relation to this information is determined by their needs, generated from the methodological requirements of the activities to be carried out, the existing conditions for their performance, and the socio-psychological characteristics of each one. According to Núñez-Paula and ZayasCaballero (2013), the need for information (while learning) generates a behaviour that translates into beliefs, motivation, enthusiasm, skills and knowledge, but also an adaptability to circumstances to successfully achieve the answers to the original problem. Students, being one of the groups circulating in the academic community, do not have a linear or unique behavioural pattern. Even if integrated into the same context and under the same conditions, they are carriers of their own and unique experiences, generating performances that are also their very own, and unique. To understand the behaviour pattern of students who attend libraries, it is necessary to know their motivations and their perceptions, and their levels of satisfaction with the service provided (Rapchak et al., 2018).

Libraries have a mission to satisfy all those who use their space and services; a satisfied user will pass on a positive opinion to others, but a dissatisfied user will pass on a negative opinion to many more. Hernon and Altman (1996) state that 'many libraries consider customers poor judges of the quality of information services... what the customer thinks about both the process and the outcome of the service is the important issue in customer's perceptions' (p. 7). In the 
context of academic libraries, students may express a favourable or unfavourable opinion about the services provided by a library; this opinion will prevail as a determinant of the quality of the service, regardless of the beliefs of the organization. It means that if students are satisfied with the service provided and with the response obtained, 'satisfaction is a sense of contentment that arises from an actual experience in relation to an expected experience' (Hernon and Whitman, 2001, p. 32). According to Lopes (2006), the most important thing in the future for libraries will not be the possession of books or access to sophisticated information technologies but having the largest number of regular users who are highly satisfied with the products and services made available. In this context, the intention of the user satisfaction studies that have been developed in academic libraries is to identify areas of scrutiny and measure the usability of services by the academic community. Lopes considers that this is an evaluation process, which encompasses the users' view, underlying a strategy of orientation on the part of the library, in the search to serve users and to gain users' satisfaction (Lopes, 2006).

In the current context of great transformations and human and social adaptation, it is important to know the work developed by academic libraries to respond effectively to their first and final clients: the students. It has never made so much sense to understand the perception and needs of users and potential users so that organizations, respecting their mission, can fulfil what people expect from them and which gives them a reason to exist, understanding if the information passes in time and without noise, and identifying who is doing this work in the institutions.

In this scenario, COVID-19 closed academic libraries in early March 2020 for an indefinite period (IFLA, 2020). With no time to plan, libraries were physically shut down to protect the security of the entire academic community and turned into online services to allow remote working. All the work done over the years curating digital content, building robust formative strategies with students, making them aware of electronic resources, defining typologies and suitability, providing information literacy skills, has seemingly been a successful project, reassuring librarians, and libraries.

Faced with COVID-19 and social isolation, academic students were suddenly confined to distance learning. Academic institutions reinvented themselves, finding ways of providing their services remotely. 
In this context, the three academic institutions under analysis (a public college, a public polytechnic institute, and a private university institute), located in Lisbon (Portugal), with a total population of 15,399 undergraduate and master's degree students from diversified fields of knowledge (Arts, Health Sciences, Business Sciences, Communication, Education, Engineering, and Psychology), reinvented themselves and adapted to the pandemic scenario. Integrating the practice of teaching that underpins the formation of the individual, promoting citizenship, and encouraging the active participation of students in the institution and the community, in the field of services, research, development, culture, and artistic creation, never has the mission of these three institutions of higher education made so much sense.

It is therefore important to determine student satisfaction for the institutions and in particular for their libraries: whether or not their information needs are satisfied; whether they know what the reliable sources of information are; if they feel their information needs are satisfied; if they feel supported in the information evaluation process; if they consider that the reference interview, carried out remotely, is satisfactory and meets their demands. The restrictions on physical access to the campuses of the three institutions and their ten libraries, and specifically to face-to-face services, have created challenges for the management of the organization and the functioning of its services, especially to students.

Thus, the objectives of this study were:

1. To perceive the satisfaction of academic students over libraries' responses to their information needs, whether at the level of services or through electronic resources.

2. To assess whether academic students consider themselves prepared to search, assess, and manage the retrieved information now that they work autonomously and depend exclusively on digital content.

These goals are intended to answer the question: will academic students be satisfied with the distance services offered by their libraries during the current pandemic? The answer will allow us to identify the expectations and difficulties perceived by students and help to identify ways of improving the delivery of face-to-face and distance services of academic libraries.

\section{Methods}


In this section, we will include details of the questionnaire as well as data collection and analysis.

\subsection{Participants}

The sample is non-probabilistic and consists of 434 students from the three institutions (Table 1).

Table 1. Descriptive characteristics of analysis sample $(N=434)$

\begin{tabular}{|c|c|c|c|}
\hline Variable & \multicolumn{3}{|c|}{ Summary value } \\
\hline \multicolumn{2}{|l|}{ Gender } & Freq. & $\%$ \\
\hline Female & & 341 & $(78.6 \%)$ \\
\hline Male & & 91 & $(21 \%)$ \\
\hline Other/Prefer not to say & & 2 & $(0.4 \%)$ \\
\hline \multicolumn{4}{|l|}{ Age } \\
\hline Mean Age (SD), years & (Range 17-77) & 23.81 & 8.597 \\
\hline \multicolumn{4}{|l|}{ Cycle of study } \\
\hline \multirow{4}{*}{ Undergraduate students } & $1^{\text {st }}$ year & 188 & $(54.7 \%)$ \\
\hline & $2^{\text {nd }}$ year & 44 & $(12.8 \%)$ \\
\hline & $3^{\text {rd }}$ year & 94 & $(27.3 \%)$ \\
\hline & $4^{\text {th }}$ year & 18 & $(5.2 \%)$ \\
\hline \multirow{2}{*}{ Master students } & $1^{\text {st }}$ year & 67 & $(74.5 \%)$ \\
\hline & $2^{\text {nd }}$ year & 23 & $(25.5 \%)$ \\
\hline \multicolumn{4}{|l|}{ Institutions } \\
\hline Inst. Politécn. Lisboa & Polytechnic institute & 198 & $(45.6 \%)$ \\
\hline ISPA & Private university institute & 201 & $(46.3 \%)$ \\
\hline Inst. Educação & Public college & 35 & $(8.1 \%)$ \\
\hline
\end{tabular}

\subsection{Instrument}

A student evaluation questionnaire was designed on Office forms (see the questionnaire in supplementary material). The questionnaire was circulated in the three institutions, through institutional email, firstly in the second half of May 2020, a period that covered the beginning of social confinement in Portugal, but in which teaching activities continued remotely libraries continued to provide services at a distance. The questionnaire was circulated again in October 2020 , at the beginning of the academic year, when students adopted new learning practices marked by the division of classes and by physical attendance alternate weeks.

The questionnaire identified the objectives of the study and stated the ethical approach regarding anonymity and confidentiality of data. It was structured in four sections: 1) the 
satisfaction of libraries' responses to information needs; 2) the satisfaction over electronic resources made available by libraries; 3 ) the self-perceived assessment of students' information skills; and 4) socio-demographic data.

2.2.1. The aim of the libraries' response to information needs was to assess student satisfaction regarding access to electronic resources from home, information obtained through library websites, how to retrieve information (catalogues, databases), the digital resources made available, and, in general, the support provided by library teams. To express respondents' degrees of satisfaction a Likert scale was used: 1 . Completely unsatisfied; 2. A little unsatisfied; 3. Reasonably satisfied; 4 . Very satisfied; 5 . Completely satisfied.

2.2.2. In view of the electronic resources made available by the libraries, the aim was to assess the degree of student satisfaction with digital resources such as library catalogues, B-ON (a Portuguese consortium that ensures access to a vast number of scientific journals and electronic services to the national academic and scientific community - see www.b-on.pt), PubMed, Scopus, Web of Science, E-books Academic Collection, RCAAP (a portal which aims to collect, aggregate and index open access scientific contents from Portuguese institutional repositories - see https://www.rcaap.pt/). It constitutes a single-entry point for searching, discovery and recall of thousands of scientific and scholarly publications, namely journal articles, conference papers, thesis, and dissertations, distributed by several Portuguese repositories), SciELO and others. To express their degree of satisfaction, students used the same Likert scale. It should be noted that the term 'library catalogue' has been changed to 'library database', as the term 'catalogue' has, for the academic community, a different connotation.

2.2.3. Because students access the libraries' electronic resources in a remote, independent way, their level of satisfaction with the stages of the search, assess and retrieve information and their information skills was evaluated using a Likert scale (1. I completely disagree; 2 I disagree; 3 . I neither agree nor disagree; 4 . I agree; 5 . I completely agree).

2.2.4. The socio-demographic data collected age, gender, the cycle of studies, and course year data.

\section{Results}


Overall, $88 \%$ of students are reasonably, very, or completely satisfied with access to electronic resources from home. This figure drops a little (83.6\%) over the degree of satisfaction with the information obtained from the library website (Table 2).

Table 2. The libraries' response to information needs by study cycles

\begin{tabular}{|c|c|c|c|c|c|}
\hline & Undergradua & udents / Mas & tudents & & \\
\hline & 1 & 2 & 3 & 4 & 5 \\
\hline $\begin{array}{l}\text { 1. Your satisfaction in accessing } \\
\text { electronic resources from home }\end{array}$ & $4.65 / 5.55$ & $8.43 / 2.22$ & $32.27 / 16.67$ & $35.46 / 45.56$ & $19.19 / 30.00$ \\
\hline $\begin{array}{l}\text { 2. Your satisfaction with the } \\
\text { information obtained through the } \\
\text { library website }\end{array}$ & 3.49 / 5.55 & $13.66 / 7.78$ & 37.50 / 18.90 & 31.10 / 53.33 & $14.25 / 14.44$ \\
\hline $\begin{array}{l}\text { 3. Your satisfaction with the way to } \\
\text { recover information (catalogues, } \\
\text { databases) and to use it }\end{array}$ & $3.20 / 5.56$ & $8.43 / 4.44$ & 44.48 / 34.44 & 30.23 / 37.78 & $13.66 / 17.78$ \\
\hline $\begin{array}{l}\text { 4. I am satisfied with the digital } \\
\text { resources made available by the } \\
\text { Library because they helped me with } \\
\text { my information needs }\end{array}$ & $5.81 / 6.67$ & $12.80 / 4.44$ & $30.81 / 22.22$ & 33.43 / 45.56 & $17.15 / 21.11$ \\
\hline $\begin{array}{l}\text { 5. I am satisfied with the support } \\
\text { provided by the library team }\end{array}$ & $3.78 / 4.44$ & 7.27 / 5.55 & $34.01 / 20.00$ & $29.36 / 38.90$ & $25.58 / 31.11$ \\
\hline
\end{tabular}

Note: Likert scale: 1 . Completely unsatisfied; 2 . A little unsatisfied; 3 . Reasonably satisfied; 4 . Very satisfied; 5 . Completely satisfied. Percentage values.

Of the total responses, $88.7 \%$ were positive about how to retrieve information through databases and $53.9 \%$ are very or completely satisfied with the digital resources made available, because they feel they have helped them respond to their information needs.

Regarding the support provided by the library team during the pandemic period, $88.9 \%$ of the undergraduate students and $90 \%$ of the master's students express satisfaction.

Most libraries develop training sessions on the resources made available, in the library space, but also in a classroom context, in a culture of close collaboration with teachers. The contents are varied, as well as their duration. This study highlights the percentage of students who are unaware of the existence of some databases (Table 3); and because they are unaware, they do not answer the question. Undergraduate students are unaware of access to Scopus with 58.14\%, RCAAP with 54.94\%, PubMed with 51.46\%, Web of Science with 50.87\%, e-books database with $50.29 \%$, and B-ON with $43.31 \%$. More than half of the master's students do not know that they have access to Scopus (52.22\%), PubMed (44.45\%), and the Web of Science 
(38.89\%), exactly the three most important databases for the rationale of their research work. The library database is also unknown to $29.5 \%$ of students; it is also the database with the highest percentage of dissatisfaction among the total number of students.

Table 3. Assessment of student satisfaction with the electronic resources made available by libraries

\section{Your satisfaction with the electronic resources made available by libraries (\%)}

\begin{tabular}{|c|c|c|c|c|c|c|}
\hline & \multicolumn{6}{|c|}{ Undergraduate students / Master students } \\
\hline & 1 & 2 & 3 & 4 & 5 & NS/NR \\
\hline Library database & $2.91 / 5.56$ & $7.85 / 3.33$ & $29.65 / 18.89$ & $27.33 / 38.89$ & $9.59 / 20.00$ & $22.67 / 13.33$ \\
\hline $\mathrm{B}-\mathrm{ON}$ & $2.62 / 4.44$ & $6.98 / 3.33$ & $20.93 / 15.56$ & $20.06 / 30.00$ & $6.10 / 17.78$ & $43.31 / 28.89$ \\
\hline PubMed & $2.03 / 6.67$ & $2.91 / 1.11$ & $18.02 / 12.22$ & $17.73 / 22.22$ & $7.85 / 13.33$ & $51.46 / 44.45$ \\
\hline Scopus & $2.03 / 4.44$ & $2.62 / 1.11$ & $17.73 / 13.33$ & $14.54 / 18.90$ & $4.94 / 10.00$ & $58.14 / 52.22$ \\
\hline Web of Science & $2.03 / 5.56$ & $2.33 / 2.22$ & $20.06 / 13.33$ & $17.15 / 23.33$ & $7.56 / 16.67$ & $50.87 / 38.89$ \\
\hline E-books Academic Coll. & $2.32 / 3.33$ & $3.49 / 3.33$ & $21.22 / 14.45$ & $15.99 / 27.78$ & $6.69 / 13.33$ & $50.29 / 37.78$ \\
\hline RCAAP & $2.32 / 3.33$ & $3.49 / 4.44$ & $16.57 / 10.00$ & $14.83 / 25.56$ & $7.85 / 26.67$ & $54.94 / 30.00$ \\
\hline SciELO & $3.20 / 4.45$ & $3.20 / 2.22$ & $20.64 / 13.33$ & $21.22 / 32.22$ & $14.82 / 25.56$ & $36.92 / 22.22$ \\
\hline Other electronic resources & $2.62 / 2.22$ & $3.78 / 2.22$ & $20.35 / 17.78$ & $22.38 / 30.00$ & $12.21 / 24.45$ & $38.66 / 23.33$ \\
\hline
\end{tabular}

Note: Likert scale: 1. Completely unsatisfied; 2 . A little unsatisfied; 3 . Reasonably satisfied; 4. Very satisfied; 5 . Completely satisfied. The option Does not know / Does not answer (NS/NR) was also included. Percentage values.

Of the electronic resources subscribed, B-ON is the best-known resource and with which master students feel most satisfied (30\%). As far as open access resources are concerned, $56.6 \%$ of undergraduate students, who know and use them, are reasonable, very, or completely satisfied with SciELO, 43.6\% with PubMed, and 39.24\% with RCAAP. Masters' students who know and use open access resources show reasonable or complete satisfaction with SciELO (71.1\%), RCAAP (62.2\%), and PubMed (47.7\%).

Regarding the difficulties experienced, undergraduate students highlight the library database $(10.7 \%)$ and B-ON (9.5\%), while masters students also refer to the library database $(8.8 \%)$ and then B-ON, PubMed, Web of Science and RCAAP (resources presenting the same percentage of difficulty: $7.7 \%)$.

Undergraduate students who know the electronic resources presented are reasonably, very, or completely satisfied with the library database (66.5\%), SciELO (56.68\%), other electronic resources made available (54.94\%), B-ON (47.09\%), Web of Science (44.76\%), E-books Academic Collection (43.89\%), PubMed (43.6\%), RCAAP (39.24\%) and Scopus (37.2\%). Regarding master's students, they are reasonably, very, or completely satisfied with the library database $(77.7 \%)$, 
other electronic resources (72.2\%), SciELO (71.1\%), B-ON (63.3\%), RCAAP (62.2\%), E-books Academic Collection (55.5\%), Web of Science (53.3\%), PubMed (47.7\%), and Scopus (42.2\%).

Analyzing the degree of student satisfaction with their information skills, by accessing electronic resources in a remote, autonomous way, students express agreement and an absolute agreement about their abilities to perform information searches $(91.24 \%)$, the master's students being the ones who demonstrate the highest security (94.4\%) (Table 4).

Table 4. Level of student satisfaction with their information skills

\begin{tabular}{|c|c|c|c|c|c|}
\hline \multicolumn{6}{|c|}{ you feel about your information skills? (\%) } \\
\hline & 1 & 2 & 3 & 4 & 5 \\
\hline $\begin{array}{l}\text { I feel comfortable doing information } \\
\text { searches }\end{array}$ & $2.32 / 1.11$ & $\begin{array}{c}7.27 / \\
4.44\end{array}$ & $21.51 / 6.67$ & 48.55 / 61.11 & $20.35 / 26.67$ \\
\hline $\begin{array}{l}\text { I know how to recognize reliable information } \\
\text { for my field of study }\end{array}$ & $2.03 / 1.11$ & $\begin{array}{c}4.94 / \\
3.33\end{array}$ & 23.84 / 14.45 & $54.07 / 57.78$ & $15.12 / 23.33$ \\
\hline $\begin{array}{l}\text { I can assess the importance of different } \\
\text { information resources }\end{array}$ & $1.45 / 0.00$ & $\begin{array}{c}6.11 / \\
2.22\end{array}$ & $18.31 / 7.78$ & $57.27 / 52.22$ & $16.86 / 37.78$ \\
\hline $\begin{array}{l}\text { I recognize the importance of correctly and } \\
\text { adequately citing the work of others }\end{array}$ & $0.58 / 0.00$ & $\begin{array}{c}2.62 / \\
0.00\end{array}$ & $10.47 / 1.11$ & 42.73 / 43.33 & $43.60 / 55.56$ \\
\hline $\begin{array}{l}\text { I try to refer correctly and properly with the } \\
\text { requested referencing style }\end{array}$ & $1.16 / 0.00$ & $\begin{array}{c}2.04 / \\
1.11\end{array}$ & $9.88 / 2.22$ & $45.35 / 40.00$ & 41.57 / 56.67 \\
\hline
\end{tabular}

Note: Likert scale: 1 . I completely disagree; 2 . I disagree; 3 . I neither agree nor disagree; 4. I agree; 5 . I completely agree. Percentage values.

Regarding the recognition of reliable scientific literature for their field of study, $71.6 \%$ of students show agreement or an absolute agreement. Also, in this parameter, the master's students, most of whom are already professionals, reveal $81.1 \%$ of certainty in their response.

Of the group of students, $77.4 \%$ agree and agree absolutely in the assessment of the importance of the different information resources, but the master's students answer with $90 \%$, revealing to be able to distinguish and assess the importance of an article, book, chapter, or thesis for their different works. They are also those who, in an almost absolute way (98.8\%), recognize the importance of correctly and adequately citing the work of others.

In general, the average information skills shown are positive: close to level 4 in most parameters and for all students and clearly above level 4 in the parameters of citation and bibliographical reference for master's degrees. Nevertheless, in the assessment of students' self- 
perception of their skills, and on a scale of 0 to 10 points, the average is 7.0 with master's students slightly higher (7.3) (Figure 1).

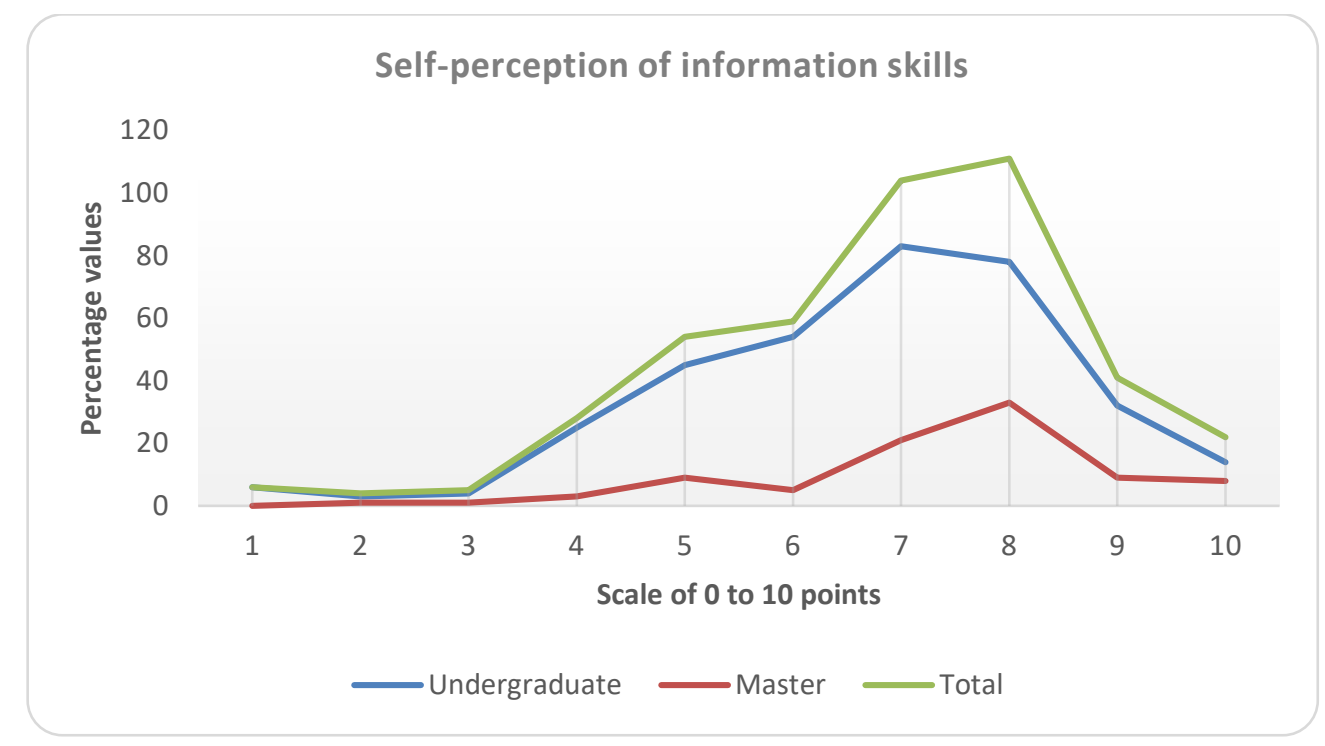

Figure 1. Students' self-perception of information skills.

At the end of the questionnaire, the students were asked about the greatest difficulties that had been experienced in searching and retrieving information, the answer being intentionally left open. The analysis of the answers allowed listing a set of concerns described in Table 5.

Table 5. The students' concerns regarding search and information retrieval

\section{Students' concerns regarding search and information retrieval}

- How to locate Portuguese scientific information.

- Do not know where to search.

- How to work with so much information.

- How to select the best one from so many databases and frame it in the subject under study.

- How to define the most appropriate keywords.

- How to build a search equation.

- The time spent in the search.

- How to find resources that are reliable and of quality.

- Understanding the relationship between keywords and resources.

- How to extract the results. 


- There are so few electronic books.
- $\quad$ The dispersed and user-unfriendly access to scientific works and with much
access/consultation restrictions.
- $\quad$ B-ON does not give access to all full-texts.
- $\quad$ The location of references available only in printed books.
- $\quad$ Do not know that one could remotely access the contents.
- $\quad$ Do not have a priori materials, tutorials, and other kinds of help.
- $\quad$ Ignorance of the existence of VPNs.
- $\quad$ Low to work with the VPN.
Lack of time.
- $\quad$ Training is necessary!

It should be noted that only $30.1 \%$ of students responded that they had not experienced any difficulties in researching and retrieving information; of these, $24.4 \%$ were undergraduate students and $5.7 \%$ were master students.

\section{Discussion}

Academic institutions, libraries, and their students are being affected not only by the COVID-19 pandemic and social confinement, but also by progressive and adaptable deconfinement. But this is the opportunity for libraries to demonstrate that, even behind closed doors, they continue to provide essential services to ensure access to reliable sources of information for the academic community and to provide information skills, even remotely; this is the opportunity to rethink access to information, which is not free from doubts, technological difficulties, and asymmetry of knowledge (Tanus and Sánchez-Tarragó, 2020).

The use of electronic resources has exploded in all academic libraries. However, the results regarding their use are not favourable to the student community, because they reveal ignorance of their existence. The percentage is high, which is worrying. These figures must be carefully analyzed as they imply the planning of a formative and pedagogical intervention that will guarantee the resolution of this problem. Electronic resources are subscribed in a global way in 
the three institutions with the objective of supporting the study and research of the entire academic community. The data in the present chapter points to a concern resulting from the students' ignorance of the resources made available by the institutions; it means that dissemination actions are not effective in reaching all interested parties, a problem that needs addressing urgently.

It seems logical that PubMed, a biomedical database is used mainly by students of Health Sciences, Dance, Biomedical Engineering, and Psychology. It is not surprising, therefore, that such a high percentage of ignorance of its existence is recorded. On the other hand, such a significant lack of awareness of Scopus on the students' side, a database to which everyone has had access in recent years, is worrying and shows that the work of dissemination and training should be rethought.

In addition to the databases subscribed to by libraries and open access resources, students were also questioned about other electronic resources. The aim was to find out what other resources (other than printed resources) students consulted at home, focusing on the digital content that was made available during the pandemic via open access or a Virtual Private Network.

In the same context, and analyzing qualitatively the answers to the open question, students reported having many difficulties searching for information, $t$ organizing their stages, defining the most appropriate and representative keywords, building a search equation, knowing what is most appropriate, determining which information is most reliable, understanding why there is open and closed content, safeguarding search results in a reference manager, installing and using a VPN. This scenario identifies the lack of dissemination, the lack of knowledge, and the lack of training of students. It is therefore necessary and urgent to define an intervention strategy in information literacy skills.

As far as the libraries' website is concerned, it will strategically have to be viewed as a gateway into virtual space. Over the years, this issue has not received the prominence it deserves, but libraries must take an interventionist role and rethink their websites now that they represent one of the main paths of interaction with students in distance learning. Following the principles of usability, libraries' websites should become easier to use.

Libraries have, over the last decade, developed an alternative but secure way of disseminating research through their institutional repository, also supporting open access 
publishing. This is the time to strengthen the dissemination of these utilities to the academic community. As an aggregating portal, RCAAP is, because of the results obtained, still unknown to most students; it is imperative to make it known, stimulating the research of academic products and the increase of research skills.

In the coming years, higher education will have to consider greater investment in the development of electronic content, which may be a challenge in the face of decreasing budgets. More than ever, libraries need not only the support of a network of libraries, librarians, and content publishers, but also organizational leaders to plan and manage their response and ensure continued access to information for students, wherever they are. Responding positively to the students' information needs has been the planning strategy of libraries in higher education over the years. In future, greater access to streaming media and electronic books, which are abundant and relatively negotiable with publishers, should be considered.

Placing librarians in the flow of the teaching-learning process has also been a trend for years in academic institutions. However, not all academics recognize this performance and not all librarians have access to the classroom, limiting themselves to the reference meeting in the library space. Providing information literacy skills, leading students to look at information resources more critically, stimulating reflective analysis of results, evaluating them, quoting them, and referencing them in an ethical, legal, and responsible manner are skills and behaviours that need to be inculcated in students (García-López, Martínez-Cardama and Pacios, 2019). This guarantees a safer way of being, especially when, in times of confinement, it is necessary to work individually and remotely.

If classes are kept at a distance, deeper integration of both library resources and librarians into undergraduate and master's course management systems is essential to ensure the acquisition of information literacy skills by students. And although in some cases there has already been online training in this area, librarians can create and streamline a closer and more effective collaboration with teachers, designing the strategy for exploiting digital content in the axis of research, location, assessment, and use of information by students (Downie, 2007). The leaders of the organization will be responsible for recognizing and formalizing this intervention.

\section{Conclusion}


The perception of academic students concerning their libraries response to COVID-19 is satisfactory, recognizing support received as being positive. However, the use of available electronic resources has not been as expected; most students are unaware of the availability of reference databases on campus and the possibility of using them remotely. As for information literacy skills, students manifest a positive self-perception of their knowledge and skills regarding research, retrieval, citation, and referencing of information. But, when expanding their responses through the open answers, numerous difficulties and asymmetries were identified.

To mitigate some of these problems immediately, strategies were created to allow dialogue with students and improve their online interactions with available resources:

i. At the polytechnic institute, for each information resource, a reference librarian and a unique email were identified. The resources and their emails were disseminated by the community, enabling each student to contact the appropriate professional to answer their questions and problems. Distance training (via Zoom, Teams, and Skype) and real-time training on each database, both in a class context and in customized meetings with each working group, were also prioritized.

ii. The public college directed all enrollments and reference questions to the email service, with a personalized answer for each student who had questions. There was also a greater concern in providing access to the e-books acquired, highlighting one of them each month with a brief review; the objective was to disseminate the collection of electronic books and generate curiosity, stimulating usage.

iii. In the private university institute, the OpenAthens platform was used for remote access to resources, and tutorials were created oriented towards learning how to use them. Personalized service was reinforced through several channels: email, Zoom, and microsite. A green way to digitalize teaching, learning and research support documents was created. Also, the weekly meetings of the library team provided an adjustment of strategies in response to the needs of the community.

In addition to these interventions, this study aims to create deeper impacts in the medium and long term through the definition of formative and pedagogical strategies in information literacy skills among undergraduate and master's students. It is, therefore, necessary to define 
the contents to be taught, the length of sessions, and the identification of the most appropriate time for delivery within the academic year. It is also imperative that this strategy be extended and normalized, involving the various administrative units, all librarians and libraries, and all study cycles. To this end, it will be necessary to raise the awareness of the leaders of the organizations and to formally implement the proposals through institutional policies.

This study had some limitations: 1) the strictly descriptive approach of the results, through the calculation of percentages; 2 ) the period in which it was developed, in which students received many dozens of emails daily, from teachers, colleagues, and their institution, requiring extra attention so as not to lose information - the study email may have been lost; 3 ) students clearly prefer their personal email and only sporadically access institutional email.

For future development it is intended to carry out the design and formal implementation of an information literacy programme for undergraduate and master's students, analyzing $a$ posteriori its results. As this is an exploratory study, it is intended in future studies to analyze and validate the metric elements of the questionnaire using data analysis through descriptive and inferential statistics.

In the era of COVID-19, the role of academic libraries is essentially the same as nine months ago: to support the academic community. However, the challenge is to determine the form and content to be adopted in meeting this goal to best effect. More attention must be paid to digital resources and user education for their full access and use, in order to benefit students and contribute to their academic success.

\section{References}

Downie, J. A. (2007). Instruction design collaborations with government information specialists. Reference Services Review, 35(1), 123-136. https://doi.org/10.1108/00907320710729418

García-López, F., Martínez-Cardama, S., \& Pacios A. R. (2019). Professor - Librarian team-teaching: Online lifelong training in the University. Journal of Library \& Information Services in Distance Learning, 13(3), 294-306. http://doi.org/10.1080/1533290X.2018.1536014

Hernon, P., \& Altman, E. (1996). Quality in academic library. Norwood. 
Hernon, P., \& Whitman, J. R. (2001). Delivering satisfaction and service quality: A customer-based approach for libraries. American Library Association.

IFLA. (2020). COVID-19 and the global library field. https://www.ifla.org/covid-19-and-libraries (accessed 10.07.20).

Lopes, C. A. (2006). Qualidade de serviço em bibliotecas universitárias: Desenvolvimento e validação de um instrumento de avaliação. Salamanca: Facultad de Traducción y Documentación, Universidad de Salamanca.

Núñez-Paula, I. A., \& Zayas-Caballero, I. (2013). Perspectiva histórica y metodológica del sistema conceptual relativo al comportamiento informacional. Bibliotecas - Anales de Investigación, 8-9, 50-75.

Rapchak, M. E., Nolfi D. A., Turk M. T., Marra L., \& O’Neil, C. K. (2018). Implementing an interprofessional information literacy course: Impact on student abilities and attitudes. Journal of the Medical Library Association, 106(4), 464-470. http://doi.org/10.5195/jmla.2018.455

Tanus, G. F., \& Sánchez-Tarragó, N. (2020). Atuação e desafios das bibliotecas universitárias brasileiras durante a pandemia de COVID-19. Revista Cubana de Información en Ciencias de la Salud, 31(3), e1615. 


\section{Appendix}

\section{STUDENT SATISFACTION WITH LIBRARY IN THE COVID-19 ERA}

Faced with COVID-19 and social isolation, academic students were suddenly confined to distance learning and to use scientific and educational resources made available by academic libraries.

The aim of this questionnaire is to perceive the satisfaction of academic students over the response of libraries' responses to their information needs, whether at the level of services or through electronic resources, and to assess whether academic students consider themselves prepared to search, assess, and manage the retrieved information.

It consists of 9 questions and only one answer is expected.

The answer to the questionnaire will not take more than five minutes.

The study is confidential and guarantees the anonymity of the participants.

Thank you for your collaboration!

\section{THE SATISFACTION OF LIBRARIES' RESPONSES TO INFORMATION NEEDS}

1. Your satisfaction regarding access to electronic resources from home.*

2. Your satisfaction with the information retrieved through library website.*

3. Your satisfaction with how to retrieve information (catalogues, databases) and the way to use it.*

4. I am satisfied with the electronic resources available in the library because they help me to answer my information needs.*

5. I am satisfied with the support provided by library team.*

Completely unsatisfied

A little unsatisfied

Reasonably satisfied

Very satisfied

Completely satisfied

THE SATISFACTION OVER ELECTRONIC RESOURCES MADE AVAILABLE BY LIBRARIES DURING THE PANDEMIC

6. Electronic resources:

Library website*

B-ON*

PubMed / MEDLINE*

Scopus*

Web of Science*

E-books Academic Collection*

Institutional repository*

RCAAP*

SCIELO*

Other electronic resources*

7. Satisfaction, in general, with the electronic resources made available. ${ }^{*}$

SELF-PERCEIVED ASSESSMENT OF STUDENTS' INFORMATION SKILLS

8. How do you assess your information skills?

I feel comfortable doing information searches.*

I know how to recognize reliable information for my field of study.*

I can assess the importance of different information resources.*

I recognize the importance of correctly and adequately citing the work of others.*

I seek to correctly and adequately refer according to the requested referral standard.*

9. What were the greatest difficulties experienced in search and information retrieval?*

\section{SOCIO-DEMOGRAPHIC DATA}

\begin{tabular}{|l|l|}
\hline 10. Age & A number between $17 \sim 70$ \\
\hline 11. Sex & Do select: $M /$ F/Other \\
\hline 12. Cycle of study & Do select: Undergraduate/Master \\
\hline 13. Course year & Do select: $1 / 2 / 3 / 4$ \\
\hline
\end{tabular}

* Required answer 